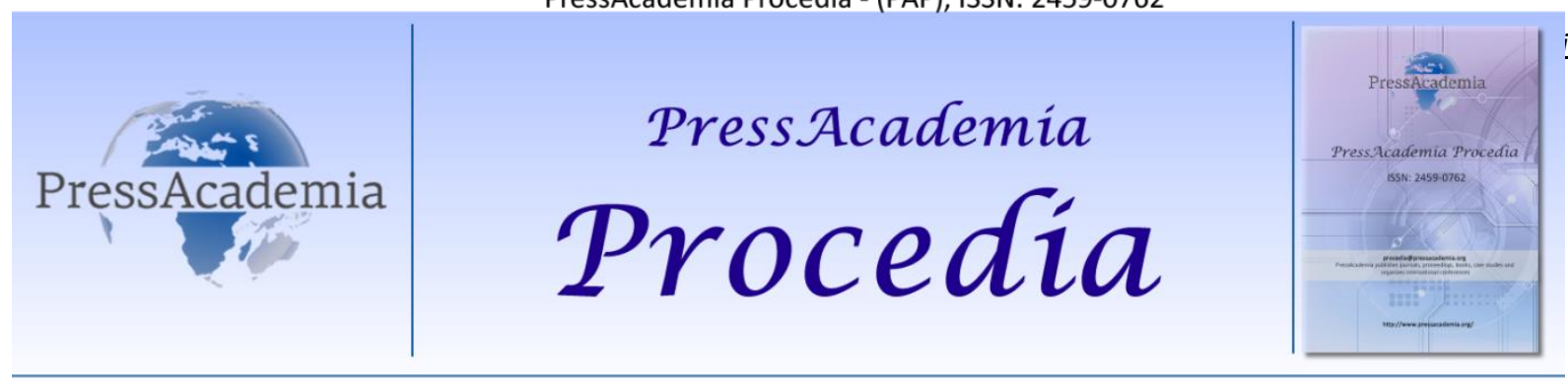

2nd World Conference on Technology, Innovation and Entrepreneurship

May 12-14, 2017, Istanbul, Turkey. Edited by Sefer Şener

\title{
BOOSTING ENTREPRENEURSHIP IN GEORGIA DEVELOPMENT OF FAB LABS
}

\author{
DOI: 10.17261/Pressacademia.2017.512 \\ PAP-WCTIE-V.4-2017(4)-p.29-33
}

\section{Giorgi Benashvili}

MA researcher of Tbilisi State University. giorgi.benashvili@tsu.ge

\begin{abstract}
Boosting entrepreneurship has a crucial meaning for long-term economic development. It is taken as axiomatic that innovative activity has been the single, most important component of long-term economic growth. The Fab Lab concept is to provide spaces open to the public where people can access tools, training and designs in digital fabrications, and to base this around a global network of physical workshops with access to on-line and other support services, as well as being networked with one others. Fab Labs take advantage of increasing accessibility to versatile and powerful digital design and fabrication tools. During the last few years Georgian government increase funding and state support to diffusion innovations into the economy. It's evident if we count launching the innovative laboratories in the different cities of Georgia. The network consists more than 20 labs in the country. All of them are located at the public spaces and are funding by state government. Fabrication Laboratories offer to all entrepreneurs, students, and citizens full service of product prototyping and business consulting. The article considered and discusses about the role of this innovative laboratories into the economic growth, stimulation of entrepreneurship and startup developments.
\end{abstract}

\section{INTRODUCTION}

Undoubtedly the capability to innovate and to bring innovation successfully to market will be a crucial determinant of the global competitiveness of nations over the coming decade. There is growing awareness among policymakers that innovative activity is the main driver of economic progress and well-being as well as a potential factor in meeting global challenges in domains such as the environment and health.

Job creation and productivity growth are at the forefront of today's global development agenda. According to the 2013 World Development Report on jobs entrepreneurship is mentioned as an important tool in addressing these dual goals. Entrepreneurship is the phenomenon associated with entrepreneurial activity. Entrepreneurial activity is an enterprising human action in pursuit of the generation of value through the creation or expansion of economic activity by identifying and exploiting new products, processes, or markets.

The Fab Lab concept may reflect a new manufacturing paradigm where individual entrepreneurs define problems, create solutions, and market products. A community workspace is created that serves as an incubator for research, creative endeavors, and business incubation. The Fab Lab removes barriers such as start-up funding, access to equipment, and access to expertise, thus encouraging systemic change to educational and entrepreneurial environments. Fabrication Laboratories (Fab Labs) began as an educational outreach project from MIT's Center for Bits and Atoms in 2002, with funding from the National Science Foundation. Fab Labs combine open source software with commercially available, industrial grade, rapid prototyping equipment such as computer controlled laser cutters, scanners, and milling machines. Internet and broadband conferencing capabilities link over 40 Fab Labs in 11 countries (Sun 2009; Lassiter, 2009) to enhance information sharing and informal educational opportunities. Fab Labs allow individuals to construct prototypes as long as users learn how to do the fabrication on their own and share the lab with others. Nowadays the global network of 
Fab Labs counts more than one thousand laboratories worldwide. Since 2014, Georgia become the first country in the South Caucasus, where launched first fabrication laboratory, which operated at the base of state university.

What does Innovation and Entrepreneurship means for Development?

According to the broad notion, innovation is the implementation of a new or significantly improved product (good or service), a new process, a new marketing method, or a new organizational method in business practices, workplace organization, or external relations. ${ }^{1}$ The definition of innovation has broadened- it is no longer restricted to R\&D laboratories and to published scientific papers. Innovation could be and is more general and horizontal in nature, and includes social innovations and business model innovations as well as technical ones. Last but not least, recognizing and celebrating innovation in emerging markets is seen as critical for inspiring people- especially the next generation of entrepreneurs and innovators. (Fingar, 2006)

Innovation is gaining prominence in all kinds of economic activity around the world. Not only advanced economies but also developing nations are finding that innovation is one of the main drivers of economic growth. This renewed understanding of the significance of innovation is having a growing impact on the course of policy formulation in many countries. Governments have realized that technology adoption alone is no longer sufficient to maintain a high-growth scenario; rather innovation is now crucial for catching up to high-income countries. (Cameroon, 1996)

On average, the technology gap between developing and developed countries appears to be narrowing. One explanation is that more and more developing countries outperform in innovation inputs and outputs relative to their level of development.

Another new policy development is the focus on creating an 'innovation culture' with businesses, students, and society at large. This is meant to spur greater entrepreneurial activity and to achieve a better public appreciation of the role of science and innovation. The design of proper metrics and evaluation strategies of policies is emphasized too. Indeed, the formulation and measurement of innovation policies is increasingly treated as a science in its own right. (OECD 2007)

Governments can support entrepreneurial activities in a variety of ways. At the most basic level, effective government policies can create an institutional base that establishes openness to trade, improves the business environment for domestic and foreign investment, establishes effective intellectual property rights regimes, and enhances knowledge flows and learning. Beyond those general policies, many governments have also intervened at the industry and firm levels to address market failures. Governments can also play a more direct role in fostering innovation. Public investment in science and basic research can play an important role in developing. (INSEAD, 2015)

\section{Fab Labs - A place where innovations live on}

The impact of a technological innovation will generally depend not only on its inventors, but also on the creativity of the eventual users of the new technology. Therefore, supporting diffusion of technologies can increase its impact on economics.

The concept of a Fab Lab was first imagined as the educational outreach component at the Center for Bits and Atoms (CBA) at the Media Lab of the Massachusetts Institute of Technology in USA, in 2001 by the funding support of National Science Foundations. Fab Labs and its workshop areas offering the possibility of digital fabrication and rapid prototyping to anyone interested. These are run mainly by enthusiasts called "Makers", entrepreneurs, start-up owners and such structures form a distributed network of laboratories enabling invention and providing access to an array of flexible computer controlled tools that cover several different length scales and various materials. A fab lab is per definition an open place for everyone: youth, students, researchers, entrepreneurs, startups, small \& medium enterprises and university faculty. Fab Lab is also a workplace for innovation, providing stimulus for entrepreneurship at local scales. A Fab Lab becomes a platform for learning and knowledge exchange: an open place to play, create, learn, mentor, share and invent. Fab Labs are available as a community resource, offering open access to individuals as well as scheduled access to workshops and training activities in different technological subjects. Fab Labs include tools to laser cutting, to build 2D and 3D structures, CNC milling machines that make circuit boards and precision parts, low-cost 3D printers and scanners, and a suite of electronic components and programming tools for low-cost, high speed microcontrollers and tiny computers for electronic prototyping. These machines can produce prototypes with the aim to allow making "almost anything" and to prototype and refine new ideas. These prototypes embraces technology-enabled products generally perceived as limited to mass production and experimentation.

\footnotetext{
${ }^{1}$ European Communities and the Organisation for Economic Co-operation and Development (OECD)
} 
To define a laboratory as a Fab Lab, these criteria have to be met: ${ }^{2}$

- Public access to the Fab Lab is crucial since Fab Lab is all about democratization of tools and means for invention and personal expression.

- The Fab Lab has to support and subscribe to the Fab Charter -a set of rules describing what Fab Lab is, and what is not, and what are its duties and responsibilities.

- Fab Labs have to share a common set of tools and processes to be able to produce the same thing in each and every Fab Lab in the world.

- Fab Labs must play an active part in the international Fab Lab network.

The Fab Lab community workspace removes barriers such as access to equipment and access to expertise. The Fab Lab's grassroots environment serves as an incubator for creative endeavors, job creation, economic development and research. Individuals applying scientific and mathematical principles to the practical design, manufacturing and operation of products engage in engineering activities. Some individuals become entrepreneurs as they create businesses related to marketing and selling their newly engineered creations. Thus Fab Labs help create "entrepreneurs" -individuals who design as well as market their own creations.

Fab Labs take advantage of increasing accessibility to versatile and powerful digital design and fabrication tools. The Fab Labs concept has also benefitted from a wave of social interest in making, hacking and tinkering globally. Growth in Fab Labs numbers has consequently been rapid. In 2017, there were more than 1100 laboratories in over 70 countries. $^{3}$ (Smith, 2015)

Motivated by the academic activities that are of interest to scientists and by the formation of new communities interested in science and development around Fab Labs, a Fabrication Laboratory inserted in a scientific framework can open new dimensions to science and education, inspire curiosity and offer powerful new ways to facilitate the development of new ideas with a certain impact. With the small economical investment requested to establish a Fab Lab, an academic institution, especially in developing countries, can catalyze innovation and entrepreneurship at the grassroots level with the help of its faculty and students. Fab Labs can enable researchers, students and makers in general to expand their work in new ways and to test out their ideas without breaking their budgets. These tools can also help new scholars to do science and discover it. Creativity, together with the making of ideas into fruition, is essential for progress and can help build better communities.

The goal for creating Fab Labs is to share knowledge and collaborate across international borders in the fields of science, education and sustainable growth. Whereas the life in a high-skill manufacturing Fab Lab is built upon thoughts and creation.

\section{The Role of Fab Labs in the Entrepreneurship Policy of Georgia}

The main challenge today for the government of Georgia is to find sources of long-term economic growth, particularly through private sector development. But the enterprise sector is heavily dominated by retail and other sectors that do not generate opportunities for increased trade or value added production. Continued growth will require not only higher savings and investment, but also a serious refocusing on domestic production, with an emphasis on productivity enhancements and diversification. In particular, Georgia will need to focus on supporting exports, with particular attention to improving competitiveness in the manufacturing and agriculture sectors, to spur economic growth. (Benashvili, Asanidze, 2016)

\footnotetext{
${ }^{2}$ Fab Lab Charter: http://fab.cba.mit.edu/about/charter/

${ }^{3}$ (www.fablabs.io/labs)
} 


\section{Fabrication Laboratories in Georgia}

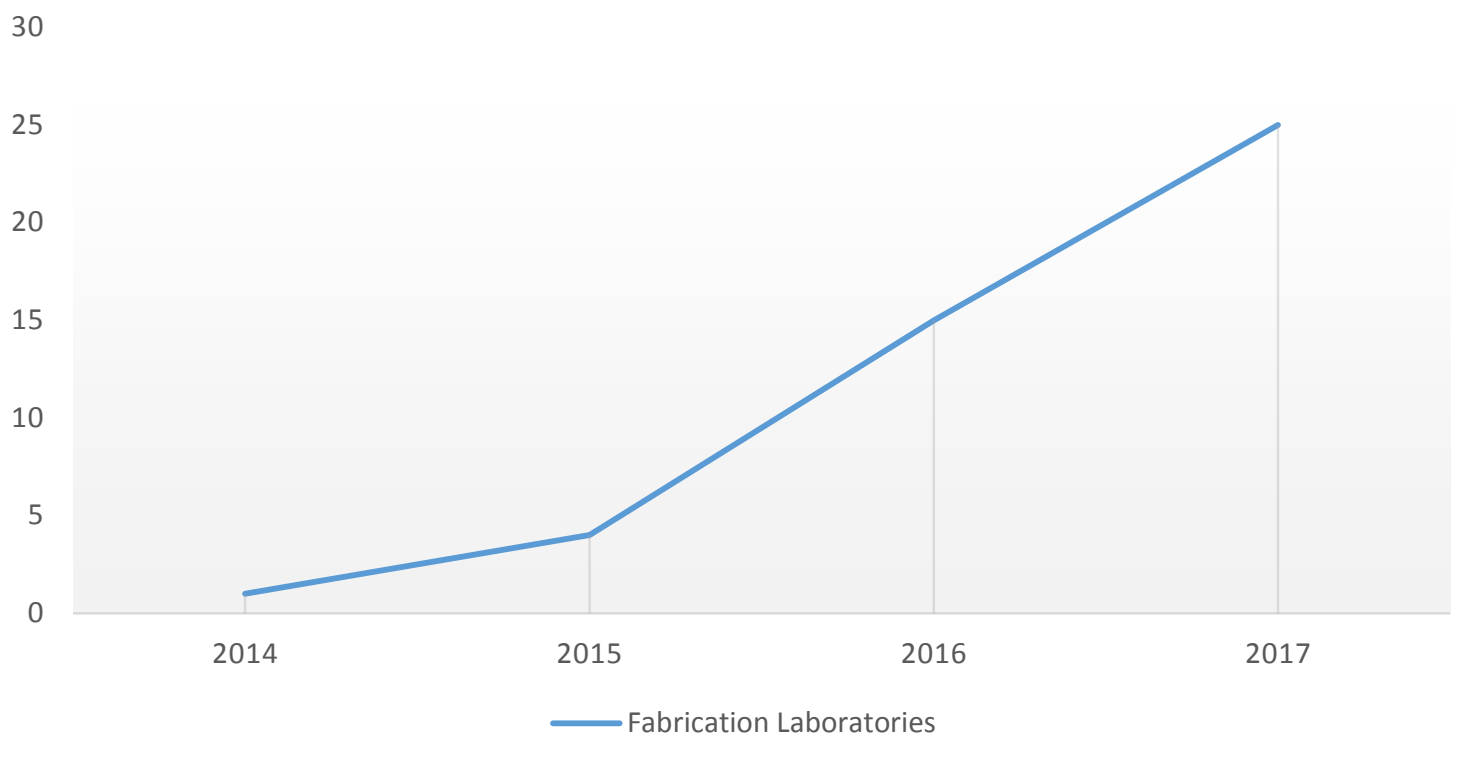

Source: Ministry of Economy of Georgia

The diffusion of technologies and boosting entrepreneurship are the directions of Georgian economic agenda. It promote start-ups and entrepreneurs very strongly to upgrade their activities. Fabrication laboratories has a crucial meaning in the chain between the technologies and entrepreneurs. The laboratories are meant to aide young innovators to turn their ideas into reality, thereby boosting economic development, start-ups and job-creation. In 2014 first fabrication laboratory was opened at Ilia State University, with financial support of Innovation and Technology Agency of Georgia. Since 2014, 14 industrial innovation laboratories-Fab Labs-opened in Tbilisi and ten other cities throughout the country today. Those modern, small-scale laboratories offering the services of 3D printers, computers and other materials, are state-funded centers of innovation hosted in many of Georgia's vocational colleges and other centers of innovation. Counting the 25 that opened today, Georgia is now in 10th place in terms of countries and the number of operating Fab Labs. Also, education is among the top priorities of the four-point strategic agenda of the Government of Georgia. (Agenda.ge, 2015)

All Fab Labs share a commitment in giving to people and helping creativity to flourish environment. During the last few years laboratories mainly located in Tbilisi become the base for many start-ups, which launched entrepreneurs. Usually, the space provides many benefits to entrepreneurs and small businesses in the city that may not have access to designated office space. On the other hand, academic institutions as Tbilisi State University successful launch business incubators. Which will create convenient atmosphere and good pre-conditions, basis for the start-uppers who have innovative business ideas. Beside the technological support from the laboratories, incubators help them in the implementation by providing full consultations pack and connections.

This movement is already afoot-professional schools and universities across the country are investing in tech-rich spaces like fabrication labs, innovation centers, and maker spaces that expose students to new technology and, most importantly, equip them with the skill sets modern workforce requires. Launching fab labs at schools and professional schools is a key priority of Georgia educational policy. Beyond that, a lot of traditional jobs have been lost to automated computer-based jobs. Part of the issue is that we don't have people who know how to operate these newer machines; there's a huge demand for those skills. A lot of students were skilled in making things with the older equipment, but not in the new ways things are being manufactured, the digital fabrication side of using 3D modeling and CAD. That's what's being tied in now.

Financial systems are not conducive to business development. Companies cite high interest rates and risk-averse lending policies (requiring high levels of collateral) as substantial hindrances to expansion. In addition, risk capital is in short supply. Few entrepreneurs reported receiving funding from the domestic financial system; most relied on their own resources to support the development of their business. During the early stages of new innovative companies, which usually have few 
or no sources of revenue and require large initial capital investments to develop their products, loan payments have a high opportunity cost. For startups that are in their nascent stages and focused on developing their first products, equity investments tend to be a better option. The government can establish favorable financing programs for SMEs ${ }^{4}$ by developing early-stage risk capital. The role of early-stage risk capital is highly relevant for innovative startups and SMEs.

Fabrication laboratories and business incubators create a possibility for start-ups to produce its goods with low expenses and it favor start-ups to increase productivity. This factors in Georgia contribute to a positive business environment for small and medium enterprises and start-ups for rapid business growth or fostering entrepreneurship.

\section{REFERENCES}

Smith, A \& Hielscher, S \& Fressoli, M (2015) Transformative Social Innovation Narrative: FabLabs. TRANSIT: EU SSH.2013.3.2-1 Grant agreement no: 613169 | 31st of March 2015" Accessed at WWW:

http://www.transitsocialinnovation.eu/content/original/Book\%20covers/Local\%20PDFs/145\%20TSI\%20Narrative_Fablabs_Upload.pdf

Fonda, C \& Canessa, E (2015) “Making Ideas at Scientific Fabrication Laboratories" The Abdus Salam International Centre for Theoretical Physics.

Kuriakose, S (2013) Fostering Entrepreneurship in Georgia, International Bank for Reconstruction and Development, Washington, USA.

OECD (2007) INNOVATION AND GROWTH RATIONALE FOR AN INNOVATION STRATEGY, OECD Publishing, Accessed at WWW: http://www.oecd.org/sti/inno/39374789.pdf

Gerguri, S and Ramadani, R (2010) "The Impact of Innovation into the Economic Growth" South East European University at Tetovo, Faculty of Business Administration, Accessed at WWW: https://mpra.ub.uni-muenchen.de/22270/1/MPRA paper 22270.pdf

Drucker P. F. (1993), Innovation and Entrepreneurship, Harper \& Row Publishers Inc., New York, USA.

Fingar, P. (2006), Extreme Competition: Innovation and the Great 21st Century Business Reformation, Meghan-Kiffer Press, Florida, USA

Horn, P., Maxwell, E. and Crawford, S. (2004), Promoting Innovation and Economic Growth: the special problem of digital intellectual property, A Report by the Digital Connections Council of the Committee for Economic Development.

Zuleeg, F. Green, J. and Schubert, B. C. (2007), Cultivating a Market for Innovation in Europe, Policy Brief of the European Policy Centre.

OECD (2012) Innovation for Development, OECD Publishing, Accessed at WWW: http://www.oecd.org/innovation/inno/50586251.pdf

Agenda.ge (2015) “New laboratory turns dreams into reality for Tbilisi entrepreneurs", News agency, Accessed at WWW: http://agenda.ge/news/46271/eng

Blikstein, P. (2013). “Digital Fabrication and 'Making' in Education: The Democratization of Invention”. In J. Walter-Herrmann \& C. Büching (Eds.), FabLabs: Of Machines, Makers and Inventors. Bielefeld: Transcript Publishers.

Cornell University, INSEAD, and WIPO (2015): The Global Innovation Index 2015: Effective Innovation Policies for Development, Fontainebleau, Ithaca, and Geneva.

Cameron, G (1996) INNOVATION AND ECONOMIC GROWTH, Centre for Economic Performance London School of Economics and Political Science, London, UK

Benashvili, G. and Asanidze, N. (2016) ECONOMIC DEVELOPMENT OF THE SOUTHCAUCASUSEAST-WEST CROSSROAD, The 2016 WEI International Academic Conference Proceedings

\footnotetext{
${ }^{4}$ Small and medium-sized enterprises
} 